\title{
Cryotherapy Following Total Knee Arthroplasty: What Is The Evidence?
}

\author{
Thacoor $A^{1}$, Back DL ${ }^{1}$, Sandiford NA ${ }^{2 *}$ \\ ${ }^{1}$ Guys and St Thomas, Hospital, Great Maze Pond, London SE1 9RT \\ ${ }^{2}$ St Georges Hospital, Blackshaw Rd, London SW17 OQT
}

Received: June 02, 2017; Accepted: February 26, 2018; Published: March 08, 2018

*Corresponding author: Mr.NA Sandiford, St Georges Hospital, Blackshaw Rd, London SW17 0QT; E-mail: nemsandiford@gmail.com

\section{Abstract}

Background: Total knee Arthroplasty(TKA) is an important option in the management of severe osteoarthritis. Despite excellent long-term results following TKA, the immediate post-operative period is often associated with pain, bleeding, oedema and reduced range of movement. Cryotherapy has been shown to provide some benefit in addressing these factors but results are largely controversial. This study aims at reviewing the current existing literature on the effects of cryotherapy following TKA.
\end{abstract}

Methods: A comprehensive review of the current literature on the use of cryotherapy in knee arthroplasty was performed. The literature search was performed using PubMed, Cochrane Library, Google Scholar and cross references using the search words "cryotherapy" AND "knee arthroplasty" for articles published between January 1990 and November 2016.

Results: A total of 28 articles were analysed and 21 of them were selected based on clinical relevance.

Conclusion: Immediate and early post-operative management following TKA remains challenging. Cryotherapy has been shown to have some benefits but the severe lack of Level 1 studies supporting its use make it difficult to reach a suitable conclusion. Further multicentre randomised controlled trials with representative populations and fair comparison of devices is needed.

Keywords: Total knee Arthroplasty; Cryotherapy; Pain.

\section{Background}

Osteoarthritis $(\mathrm{OA})$ of the knee is one of the leading causes of disability worldwide [1]. The age standardised incidence of knee $\mathrm{OA}$ is $3.8 \%$ across the world and $80 \%$ of patients over the age of 75 have radiological-proven OA [2]. Knee OA can lead to severe pain and loss of function.

Total knee arthroplasty (TKA) is one of the major options for the management of end-stage knee OA [3]. Excellent improvement in pain, mobility, quality of life and function have been reported both in the early (within three to six months post-operatively) and long term up to following this procedure [4]. Despite the encouraging results of TKA, the immediate post-operative period is often associated with significant issues such as pain, surgical blood loss and localised oedema resulting from tissue damage and the inflammatory response [5]. These are considered crucial factors due to their influence on post-operative opiate use, requirement for blood transfusion and its associated risks as well as a negative impact on post operative rehabilitation [6]. This can result in increased length of stay and increased cost to the treating unit [7].

In spite of progress in anaesthesia and multi-modal pain management, TKA remains a challenging procedure for many patients. This has led to the use of non-pharmaceutical management adjuncts such as cryotherapy to address the immediate post-operative concerns described above.

The aim of this paper is to review the role of cryotherapy, the proposed pathophysiology behind its use, its evolution with time and a review of the existing literature on its efficacy and potential risks associated with its use following total knee arthroplasty.

\section{Methods}

A review of the current English language literature relating to the use of cryotherapy following total knee arthroplasty was performed. The literature search was carried out using PubMed, Cochrane Library, Google Scholar and cross references using the search words "cryotherapy" AND "knee arthroplasty" in the abstract/title of articles published between January 1990 and November 2016. This search yielded a total of 28 articles. These were reviewed and 21 of them were selected for further review based on clinical relevance.

\section{Physiology of Action}

Cryotherapy involves the application of cold to the skin surrounding inflamed soft tissues and joints. The theoretical physiological benefits of clinical cryotherapy have been widely documented since its use in the 1960's and the effects of ice have been demonstrated in several animal and human studies $[8,9]$. The proposed mechanism of action is that a reduction in temperature reduces intra-articular temperature and limits pain through reducing nerve conduction velocity in addition to promoting immediate vasoconstriction, reducing vascular spasm and slowing down of blood flow, ultimately decreasing tissue oedema [10].

The intra-articular temperature reduction is transient [11]. 
Studies in animal models have demonstrated that excessively low temperatures or prolonged cooling results in a paradoxical increase in local oedema [12]. Despite immediate vasoconstriction and reduction in blood flow, cryotherapy could lead to delayed vasodilation and disruption of secondary haemostasis. Evidence also exists, showing that local application of ice could impair haemostasis, leading to prolonged bleeding time, increased clotting time, reduced platelet aggregation and increased clot formation time although this has not been shown to be an issue in patients without pre existing coagulopathy [13].

Some authors have reported limited benefit of cryotherapy on alleviating pain or reducing blood loss and inconsistent findings on decreasing swelling and improving mobility post TKA. The following discussion addresses these issues [14-16].

\section{Results}

[Table 1]

Table 1: Summary of results from existing literature

\begin{tabular}{|c|c|c|c|c|c|c|c|}
\hline Author & Year & Study Type & $N=$ & $\begin{array}{c}\text { Significant } \\
\text { Benefit in Pain }\end{array}$ & $\begin{array}{l}\text { Significant Benefit } \\
\text { in Blood Loss }\end{array}$ & $\begin{array}{l}\text { Significant Benefit } \\
\text { in Oedema }\end{array}$ & $\begin{array}{c}\text { Significant } \\
\text { Benefit in ROM }\end{array}$ \\
\hline Adie & 2012 & Meta-analysis & 322 & No & No & No & No \\
\hline Albrecht & 1997 & Prospective RCT & 312 & Yes & - & - & Yes \\
\hline Desteli & 2015 & Prospective RCT & 87 & No & Yes & - & - \\
\hline Gibbons & 2001 & Prospective RCT & 60 & No & Yes & - & No \\
\hline Healy & 1994 & Prospective RCT & 105 & No & No & No & No \\
\hline Kullenberg & 2006 & Prospective RCT & 86 & Yes & Yes & - & Yes \\
\hline Kuyucu & 2015 & Prospective RCT & 60 & Yes & No & - & Yes \\
\hline Levy & 1993 & Prospective RCT & 80 & Yes & Yes & No & Yes \\
\hline Morsi & 2002 & Prospective RCT & 60 & Yes & Yes & Yes & Yes \\
\hline $\mathbf{N i}$ & 2015 & $\begin{array}{c}\text { Systematic review } \\
\text { of RCT }\end{array}$ & 660 & Variable & Yes & - & - \\
\hline Smith & 2002 & Prospective RCT & 84 & No & No & No & No \\
\hline $\begin{array}{l}\text { Wittig- } \\
\text { Wells }\end{array}$ & 2015 & Prospective RCT & 29 & No & - & - & - \\
\hline
\end{tabular}

\section{Pain}

Kullenberg et al observed significantly better early range of movement, pain control and patient satisfaction in patients treated with cryotherapy compared to epidural anaesthesia in 86 patients following TKA [17]. Similar findings were reported by Morsi and Albrecht who found that continuous cold application resulted in greater than $50 \%$ reduction in analgesic demands $[18,19]$. Levy and Marmar noted mild improvements in narcotic analgesia demands post-operatively when cold compressive dressings were used [20]. Ni et al found that cryotherapy decreased pain on the second post-operative day only, but not the first or third day [21].

Adie et al undertook a systematic review and meta-analysis of 11 prospective RCTs on cryotherapy post-TKA and found no improvement in pain and analgesia requirements [22]. They noted significant heterogeneity in the studies included and a lack of patient reported outcomes which potentially influences the significance of their results. Smith et al and Gibbons et al reported no significant reduction in pain using cold compression dressings when compared to a Robert Jones bandage [23, 24]. Gibbons' group applied cold therapy for $75 \%$ less time than bandages in the early post operative period.

There is growing evidence that the use of cryotherapy together with pharmaceutical analgesia is increasing in popularity although Wittig-Wells et al found no reduction in pain or improvement in patient satisfaction investigated short-term use of cryotherapy with analgesia compared to analgesia alone $[25,26]$. The number of patients included in this study was small however.

\section{Blood loss}

Levy and Marmar reported a significant reduction in post operative blood loss in patients treated with cold therapy compared to controls in a cohort of patients who underwent 10 bilateral and 80 unilateral TKA's [20]. Similar findings were reported by $\mathrm{Ni}$ et al [21]. Desteli et al assessed the effect of using cryotherapy performed both pre and post TKA [27]. They concluded that this approach was effective at reducing perioperative and post-operative haemorrhage. Similarly Gibbons et al observed less blood loss in the surgical drains of patients in the cryotherapy group [24]. Morsi also concluded that continuousflow cold therapy was advantageous in reducing blood loss following TKA [18]. 
In contrast to the above studies Smith et al and Kuyucu et al found no significant reduction in post operative blood loss with the use of cold therapy although analgesic requirements in patients recieving cryotherapy was significantly reduced $[15,22]$.

\section{Post Operative Swelling}

Relatively few authors have investigated the effects of cryotherapy on post-operative swelling and oedema. Smith et al found limited benefit of using cold therapy when compared to compression bandages up to 48 hours post TKA in their randomised controlled trial [23]. Contrasting results were reported by Healy where a positive effect was noted with cryotherapy only when ice was exchanged every 1-2hours and a negative effect in the other patient group where ice was exchanged less frequently every $4 \mathrm{~h}$ [28]. Levy and colleagues reported no improvement in post-operative oedema when cryotherapy was applied [20].

\section{Range of Motion}

Kullenberg et al noted an increased range of flexion from 63 degrees to 75 degrees when cryotherapy was used post TKA in their study of 86 patients [17]. An improvement in range of motion post-operatively from 53 degrees on post-operative day (POD) 7 to 77 degrees on POD 14 in the cold compression group compared to 44 degrees of POD 7 to 65 degrees on POD 14 in the control group was noted by Levy and Marmar in their randomized controlled trial [20]. Another randomized controlled trial looking at the effects of Cryo/Cuff (Aircast, Vista, CA, USA) application noted better functional knee scores (Knee Society Scores) in this patient group [15]. These findings are however in contrast to those from Healy's study where Cryo/Cuff dressing application was not associated with increase in range of motion post-operatively at any point [28]. Similarly, Gibbons et al found no improvement in post-operative motion associated with the use of cryotherapy [24].

\section{Evolution of Cryotherapy}

Cryotherapy has gradually evolved over time. First generation cold therapy included basic gel packs and crushed ice in plastic bags. Second generation includes circulating ice water promoting cold therapy such as Cryo/Cuff while third generation devices enable electronic control of continuous cold therapy [27].

A large disparity in the use of cryotherapy worldwide exists due to conflicting evidence relating to its benefits. Third generation cryotherapy providers stated that this conflicting evidence was linked to improper cooling technique as traditional ice packs are unable to guarantee a sustained fixed temperature during cooling. This has led to the development of new advanced cryotherapy devices providing continuous extended cooling using continuous flow of cold air. Bech et al compared the use of a continuous cooling icing device (DonJoy Iceman, DJO Canada, Mississauga, $\mathrm{ON}$ ) against intermittent cooling via a standard ice bag in the first $48 \mathrm{~h}$ post-operatively and found no difference in pain or blood loss [16]. Thienpont also noted no difference in post-operative pain, analgesic consumption, post-operative ROM, swelling or blood loss, in patients receiving advance cryotherapy versus cold packs [29]. The authors concluded that the higher economic costs of advance cryotherapy conferred no advantages over cheaper and more readily available ice packs.

\section{Cryopneumatic Devices}

Interest has recently grown in the combined use of compression and cooling therapy through Cryopneumatic devices. Maximising range of motion (ROM) is a major objective post-TKA. However, Su et al found no difference for ROM, swelling or functional testing between a cryopneumatic device (Game Ready) and ice packs [30]. Similar findings were also reported by Holmström and Härdin in a prospective, randomized controlled study for the Cryo/Cuff when compared to epidural anaesthesia following un-compartmental knee arthroplasty [31]. However, better outcomes were demonstrated in two-stage bilateral TKAs by Morsi with the use of these devices [18].

\section{Risks of Cryotherapy}

Cryotherapy does have potential risks associated with its use. Human skin can be directly affected by hypothermia. Prolonged duration and overly low temperatures applied in addition to excessively high pressures, can compromise skin circulation [27]. Frostbite occurs at temperatures around $10 \mathrm{oC}$ and prolonged cooling less than 5oC can result in necrosis and thrombosis [29]. It has been suggested that cryotherapy should be contraindicated in individuals with cold urticaria, cryoglubinemia and paroxysmal cold haemoglobinuria [24]. In addition, it has been recommended that at least 20 minutes of cessation should be encouraged between 2-hour long cryotherapy sessions [30].

\section{Conclusion}

Management of post-operative pain following total knee arthroplasty still poses a challenge. Non pharmaceutical adjuncts such as cryotherapy are becoming increasingly popular and have evolved from simple ice packs to more refined devices employing electronically controlled cold fluid or air circulation. Current published evidence supporting its use is controversial. This is potentially due to variation in the devices used and their application (type, frequency or duration). It is therefore difficult to derive a firm conclusion on the benefits of its use. Further research in the form of multicentre randomised controlled trials with representative patient populations are needed to examine the effect of cryotherapy on post operative pain management, length of stay, post operative function post total knee arthroplasty and also to compare the devices available.

\section{References}

1. Cross M, Smith E, Hoy D, Carmona L, Wolfe F, Vos T, et al. The global burden of rheumatoid arthritis: estimates from the global burden of disease 2010 study. Ann Rheum Dis. 2014; 73(7):1316-1322. Doi: 10.1136/annrheumdis-2013-204627

2. Arden N, Nevitt MC. Osteoarthritis: epidemiology. Best Pract Res Clin Rheumatol. 2006; 20(1):3-25. Doi: 10.1016/j.berh.2005.09.007

3. Ranawat CS. History of total knee replacement. J South Orthop Assoc. 2002;11(4):218-226 
4. Bourne RB, McCalden RW,MacDonald SJ, Mokete L, Guerin J. Influence of patient factors on TKA outcomes at 5 to 11 years followup. Clin Orthop Relat Res. 2007; 464: 27-31. Doi: 10.1097/BL0.0b013e318159c5ff

5. Adie S, Kwan A, Naylor JM, Harris IA, Mittal R. Cryotherapy following total knee replacement. Cochrane Database Syst Rev. 2012; (9):CD007911. Doi: 10.1002/14651858.CD007911.pub2

6. Sehat KR, Evans RL, Newman JH. Hidden blood loss following hip and knee arthroplasty. Correct management of blood loss should take hidden loss into account. J Bone Joint Surg Br. 2004; 86(4):561-565

7. Duellman TJ, Gaffigan C, Milbrandt JC, Allan DG. Multi-modal, preemptive analgesia decreases the length of hospital stay following total joint arthroplasty. Orthopedics. 2009; 32(3):167.

8. Gage AA. Cryosurgical societies: ahistorical note. Cryobiology.1989; 26(3):302-305. Doi: 10.1016/0011-2240(89)90027-8

9. Hubbard TJ, Denegar CR. Does Cryotherapy Improve Outcomes With Soft Tissue Injury? Journal of Athletic Training. J Athl Train. 2004; 39(3): 278-279.

10.Abramson DI., Chu LS., Tuck JR. Effect of tissue temperatures and blood flow on motor nerve conduction velocity. JAMA. 1966; 198(10):10821088. Doi: $10.1001 /$ jama.1966.03110230098021

11.Ohkoshi Y, Ohkoshi M, Nagasaki S, Ono A, Hashimoto T, Yamane S. The effect of cryotherapy on intra articular temperature and postoperative care after anterior cruciate ligament reconstruction. Am J Sports Med. 1999. 27 (3):357-362. Doi: 10.1177/03635465990270031601

12.McMaster WC, Liddle S. Cryotherapy influence on posttraumatic limb edema. Clin Orthop Relat Res.1980:283-287

13.Forsyth AL, Zourikian N, Valentino LA, Rivard GE. The effect of cooling on coagulation and haemostasis: should "Ice" be part of treatment of acute haemarthrosis in haemophilia? Haemophilia. 2012; 18(6):843850. Doi: 10.1111/j.1365-2516.2012.02918.x

14.Kuo CC, Lin CC, Lee WJ, Huang WT. Comparing the antiswelling and analgesic effects of three different ice pack therapy durations: a randomized controlled trial on cases with soft tissue injuries. J Nurs Res. 2013; 21(3):186-194. Doi: 10.1097/jnr.0b013e3182a0af12

15.Kuyucu E, Bülbül M, Kara A, Koçyiğit F, Erdil M. Is cold therapy really efficient after knee arthroplasty? Ann Med Surg (Lond). 2015; 4(4): 475-478. Doi: 10.1016/j.amsu.2015.10.019

16.Bech M, Moorhen J, Cho M, Lavergne MR, Stothers K, Hoens AM. Device or Ice: The Effect of Consistent Cooling Using a Device Compared with Intermittent Cooling Using an Ice Bag after Total Knee Arthroplasty. Physiother Can. 2015; 67(1):48-55. Doi: 10.3138/ptc.2013-78

17.Kullenberg B, Ylipää S, Söderlund K, Resch S. Postoperative cryotherapy after total knee arthroplasty: a prospective study of 86 patients. J Arthroplasty. 2006; 21(8):1175-1179. Doi:10.1016/j.arth.2006.02.159

18.Morsi E. Continuous-flow cold therapy after total knee arthroplasty. J Arthroplasty. 2002; 17(6):718-722
19.Albrecht S, le Blond R, Köhler V, Cordis R, Gill C, Kleihues H et al. Cryotherapy as analgesic technique in direct, postoperative treatment following elective joint replacement. Z Orthop Ihre Grenzgeb. 1997; 135(1):45-51. DOI: $10.1055 / \mathrm{s}-2008-1039554$

20.Levy AS, Marmar E. The role of cold compression dressings in the postoperative treatment of total knee arthroplasty. Clin Orthop Relat Res. 1993;(297):174-178

21.Ni SH, Jiang WT, Guo L, Jin YH, Jiang TL, Zhao Y et al. Cryotherapy on postoperative rehabilitation of joint arthroplasty. Knee Surg Sports Traumatol Arthrosc. 2015;23(11):3354-3361. Doi: 10.1007/s00167014-3135-x

22.Adie S, Naylor JM, Harris IA. Cryotherapy after total knee arthroplasty a systematic review and meta-analysis of randomized controlled trials.J Arthroplasty. 2010; 25(5):709-715.

23.Smith J, Stevens J, Taylor M, Tibbey J. A randomized, controlled trial comparing compression bandaging and cold therapy in postoperative total knee replacement surgery. Orthop Nurs. 2002;21(2):61-66.

24.Gibbons CE, Solan MC, Ricketts DM, Patterson M. Cryotherapy compared with Robert Jones bandage after total knee replacement: a prospective randomized trial. Int Orthop. 2001; 25(4):250-252.

25.Corti L. Nonpharmaceutical approaches to pain management. Top Companion Anim Med. 2014; 29(1):24-28. Doi: 10.1053/j. tcam.2014.04.001

26.Wittig-Wells D, Johnson I, Samms-McPherson J, Thankachan S, Titus B, Jacob A, et al. Does the use of a brief cryotherapy intervention with analgesic administration improve pain management after total knee arthroplasty? Orthop Nurs. 2015; 34(3):148-153. Doi: 10.1097/ NOR.0000000000000143

27.Desteli EE, Imren Y, Aydın N. Effect of both preoperative and postoperative cryoceutical treatment on hemostasis and postoperative pain following total knee arthroplasty. Int J Clin Exp Med. 2015;8(10):19150-19155.

28.Healy WL, Seidman J, Pfeifer BA, Brown DG. Cold compressive dressing after total knee arthroplasty. Clin Orthop Relat Res. 1994; (299):143146.

29.Thienpont E. Does Advanced Cryotherapy Reduce Pain and Narcotic Consumption After Knee Arthroplasty? Clinical Clin Orthop Relat Res. 2014;472(11):3417-3423. Doi: 10.1007/s11999-014-3810-8

30.Su EP, Perna M, Boettner F, Mayman DJ, Gerlinger T, Barsoum W, et al. A prospective, multi-center, randomised trial to evaluate the efficacy of a cryopneumatic device on total knee arthroplasty recovery. J Bone Joint Surg Br. 2012; 94(11 Suppl A):153-156. Doi: 10.1302/0301-620X.94B11.30832

31.Holmström A, Härdin BC. Cryo/Cuff compared to epidural anesthesia after knee unicompartmental arthroplasty: a prospective, randomized and controlled study of 60 patients with a 6-week follow-up. J Arthroplasty. 2005; 20(3):316-321. 